\title{
As profundezas vampirotêuticas do pós-humanismo de Vilém Flusser $^{1}$
}

\author{
José Geraldo da Silva JUNIOR ${ }^{2}$
}

FELINTO, Erick; SANTAELLA, Lucia. O explorador de abismos: Vilém Flusser e o pós-humano. São Paulo: Paulus, 2012.

É possível investigar o tema do pós-humanismo sob a luz do pensamento de Vilém Flusser?

É exatamente este o desafio dos pesquisadores Erick Felinto e Lucia Santaella na obra "O Explorador de Abismos: Vilém Flusser e o Pós-Humanismo". A partir de um profundo mergulho na obra do filósofo, a dupla sugere a sua leitura em convergência com as questões do pós-humanismo e da teoria da mídia alemã. Mas quem é Flusser e o que é pós-humanismo?

Vilém Flusser nasceu em Praga em 1920. Com a ascensão do nazismo na Europa foi obrigado a fugir. Emigrou para Londres em 1940 e para São Paulo em 1941 onde viveu por mais de 30 anos. A longa estada de Flusser no Brasil não implicou, todavia, em sua permanência definitiva. Autodidata, não possuía títulos acadêmicos, nem finalizou os estudos universitários. "E assim a intolerância racial que enfrentara na Europa somou-se à intolerância acadêmica característica de uma terra de bacharéis. Sua permanência no Brasil tornou-se insustentável, fazendo-o retornar à Europa, onde morreu em 1991" (FELINTO \& SANTAELLA, 2012, p. 13).

Seus ensaios iniciais sobre linguística e filosofia foram publicados em 1957 no "Suplemento Literário" do jornal O Estado de S. Paulo. Em 1962, tornou-se membro do Instituto Brasileiro de Filosofia e professor de Filosofia da Comunicação na Faculdade Armando Álvares Penteado (FAAP), em São Paulo. Em 1964, assumiu a coeditoria da Revista Brasileira de Filosofia. Dois anos depois, foi nomeado delegado especial do Ministério das Relações Exteriores para cooperação cultural com os Estados Unidos e a

\footnotetext{
1 Trabalho apresentado à terceira edição da Revista Ação Midiática - Estudos em Comunicação, Sociedade e Cultura, publicação ligada ao Programa de Pós-Graduação em Comunicação e Sociedade, da Universidade Federal do Paraná.

${ }^{2}$ Mestrando em Comunicação pela Universidade Federal do Paraná. E-mail: jota_geraldo@ @otmail.com
} 
Europa. Entre 1965 e 1970, organizou seminários e conferências no Departamento de Humanidades do Instituto Tecnológico da Aeronáutica (ITA) sobre a Filosofia da Linguagem e escreveu crônicas sobre filosofia do cotidiano publicadas na seção "Posto Zero”, da Folha de S. Paulo. Em 1972, mudou-se para a Itália e, em 1976, para a França. Entre seus livros publicados no Brasil estão: Língua e Realidade (São Paulo: Herder, 1963); A História do Diabo (São Paulo: Martins, 1965); Naturalmente (São Paulo: Duas Cidades, 1979); Pós-História (São Paulo: Duas Cidades, 1982); Filosofia da Caixa Preta - Ensaios para uma futura filosofia da fotografia (São Paulo: Hucitec, 1985); Ficções Filosóficas (São Paulo: Edusp, 1998); A dúvida (Rio de Janeiro: Relume-Dumará, 1999); Bodenlos: uma autobiografia filosófica (São Paulo: Annablume, 2007); O mundo codificado (São Paulo: Cosac Naify, 2007); O universo das imagens técnicas, elogio da superficialidade (São Paulo: Annablume, 2008) e Vampyroteuthis Infernalis (São Paulo: Annablume, 2011).

Ainda pouco reconhecido nos "tristes trópicos", o pensamento flusseriano figura na atualidade entre os mais influentes da chamada teoria da mídia alemã. Em terras germânicas, os termos Medienwissenschaft (ciência ou teoria da mídia) e Kommunikationswissenschaft (teoria da comunicação) adquiriram significações diferenciadas ao longo dos anos referindo-se, respectivamente, à circulação de sentidos e mensagens nos meios e à dimensão tecnológica, histórica e cultural dos próprios meios.

Mas "por que razão Flusser foi 'cooptado' como um pensador da mídia 'alemão'?", questionam os estudiosos brasileiros. Para eles, o sucesso do filósofo nos ambientes acadêmicos de língua alemã vai além de uma suposta afinidade do seu pensamento com o de outros teóricos identificados à teoria da mídia. Mais interessante e produtivo do que traçar influências, defendem, é pressupor que ele captara, já em suas reflexões iniciais, as energias mentais que tomariam corpo no ambiente acadêmico germânico somente nos anos 80 , além de um conjunto de questões de ordem filosófica e midiológica, como a materialidade dos meios, o tema do arquivo e a tríade armazenagem (Speicherung), processamento (Verarbeitung) e transmissão (Ubertragung).

Com relação ao pós-humanismo, os autores iniciam o aprofundamento da discussão mencionando o trabalho de um dos mais influentes estudiosos de mídia na 
Alemanha: Friedrich Kittler, e estabelecem aproximações e distanciamentos entre algumas de suas reflexões com as de Flusser.

$\mathrm{Na}$ concepção de Kittler, o homem não possui relevância fora do escopo das formas de expressão possibilitadas pelos meios tecnológicos. Para ele, os computadores, por exemplo, aperfeiçoam determinados padrões de processamento informacional que foram impostos sobre os seres humanos e adotados erroneamente como atributos humanos.

Felinto e Santaella ressaltam que Flusser conserva um humanismo inexistente no pensamento de Kittler e que a dissolução do ser humano face às tecnologias é um passo que se nega a dar. É no âmbito das noções de jogo e criatividade, em oposição a toda espécie de automatismo, que encontra o fundamental da experiência humana. Nesse contexto, criatividade significa produção do novo, diferenciação e criação de redes na dimensão digital, as quais podem contribuir para o desenvolvimento de novas e múltiplas operações cognitivas e comunicacionais entre os seres humanos.

A partir dessa passagem é possível estabelecer um diálogo de Flusser com Deleuze \& Guattari (2011) que, ao discorrerem sobre o princípio da multiplicidade das formações rizomáticas, dizem que "as multiplicidades se definem pelo fora: pela linha abstrata, linha de fuga ou desterritorialização segundo a qual elas mudam de natureza ao se conectarem às outras" (DELEUZE \& GUATTARI, 2011, p. 24).

$\mathrm{Na}$ sociedade contemporânea marcada pela presença da tecnologia a figura dos hackers é assinalada como simbólica. Prova viva da insensatez de toda delimitação de fronteira, segundo o próprio Flusser, esses seres sintetizam sua concepção de que não se trata de afirmar o humano em detrimento da máquina, mas vincular criativamente homem e aparato. Essa reflexão conduz os autores a cogitarem sobre a possibilidade de a internet ser o palco para a próxima revolução humana onde o que determinará a estrutura da sociedade não será mais a economia, mas a comunicação.

O primeiro capítulo termina com uma provocação e com um convite. "Essa é a catástrofe: que nós agora devemos ser livres", provoca Flusser. "Livres, inclusive, para deixar a confortável zona das experiências humanas conhecidas e experimentar novas identidades pós-humanas" (FELINTO \& SANTAELLA, 2012, p. 23).

A gênese do pós-humano se dá concomitantemente ao surgimento no final da década de 40 da cibernética que, ao propor uma analogia entre o funcionamento do 
orgânico e do maquínico, fez surgir uma nova forma de pensar o humano como um sistema de processamento de informação semelhante às máquinas. O termo pós-humano foi mencionado pela primeira vez em 1977 pelo teórico da pós-modernidade Ihab Hassan.

Recuperando o neologismo ciborgue (fusão de cib-ernético com org-anismo) criado em 1960, durante pesquisas promovidas pelo programa espacial norte-americano, para nomear sistemas homem-máquina autorregulativos em ambientes diversos, a bióloga Dona Haraway, em 1985, publica o "Manifesto Ciborgue" e adianta, com grande repercussão, algumas percepções e mutações em torno da condição humana que se verificariam na década seguinte.

Nesse texto, que forneceu inclusive os alicerces para o desenvolvimento do ciberfeminismo no campo dos estudos culturais, Haraway apresenta os ciborgues como seres que realmente existem, exibindo-se nas fusões do corpo com as próteses tecnológicas, projetando-se na imaginação e exprimindo-se nos discursos da cultura e da ciência.

Nos anos 90, o pós-humanismo ganha campo, e também complexidade, despertando ainda mais a atenção de artistas, filósofos e cientistas, cujos posicionamentos a respeito do tema foram agrupados em quatro blocos: a versão "cética" que ignora ou despreza o debate sobre o pós-humano, a "apocalíptica" que engloba tendências pessimistas perante a expansão tecnológica, a "popular", herdeira das concepções do ciborgue alimentadas nas ficções cyberpunk, e a "crítica" que é a que mais se aproxima das proposições de Flusser e procura novos caminhos de pensamento sobre o que significa ser humano em uma sociedade marcada por contínuas transformações biotecnocientíficas e midiáticas.

O terceiro capítulo, "Machina Speculatrix: as muitas vidas da cibernética e a morte do humano", traz uma multifacetada e analítica exposição sobre a cibernética, desde o seu surgimento como uma ciência que Norbert Wiener, seu mais conhecido criador, definiu como dedicada a abarcar todo o campo da teoria da comunicação e controle, seja na máquina, seja no animal, até seu ressurgimento como paradigma teórico no domínio dos estudos da cibercultura e, mais visivelmente, nas reflexões da nova teoria da mídia na Alemanha. 
Em seguida, é feita uma exposição sobre a "Comunicologia", uma nova ciência pensada por Flusser que, partindo do ponto de vista da comunicação, conquistaria um olhar sobre todas as ciências humanas, cruzaria fronteiras disciplinares e até mesmo revelaria outro homem, cuja imagem (Menschenbild) com o colapso do humanismo foi perdida. "Talvez possamos conquistar, no campo da pesquisa sobre a comunicação humana, uma nova imagem do homem" (FLUSSER, 2009, p. 24 apud FELINTO \& SANTAELLA, 2012, p. 58).

A senda aberta por esta "teoria geral das ciências humanas" (Allgemeine Theorie der Geisteswissenschaften) pode servir de mote para investigações futuras no campo da comunicação, principalmente para aquelas que assumirem uma perspectiva funcionalista e cibernética dos processos comunicacionais sem uma negação radical da autonomia humana, assim como Flusser, cujo pensamento se situa entre o reconhecimento da existência de determinantes tecnológicos sobre a ação dos homens e da possibilidade destes agirem autonomamente. $\mathrm{O}$ filósofo intui as limitações do humanismo na conjuntura da sociedade tecnológica avançada, mas também procura uma alternativa que não descole totalmente do paradigma vigente.

Da tensão do pós-humano com o humanismo clássico e de tensões abismais deste com outros saberes (míticos, poéticos, filosóficos) sufocados para a ascensão da ciência moderna, Flusser questiona as obsessões cientificistas hegemônicas pelo cálculo, pela técnica e pela racionalidade ilimitada sem, todavia, fazer isso para propor algo como um reino da imaginação desvairada. $\mathrm{O}$ sujeito correspondente às reflexões flusserianas no contexto da sociedade telemática é um ser híbrido, resultado do encontro criativo e dialógico do homem com a máquina.

Em "Monstros, animais e outros 'outros'", os autores exploram as (re-)significações do corpo humano no contexto das revoluções biotecnológicas e apresentam questões desafiadoras como, por exemplo: até que ponto a noção de corpo é transformada quando a pesquisa biotec demonstra a habilidade de fazer crescerem células, tecidos e mesmo órgãos em um laboratório? O que acontece com o referente de "o humano" à medida que está crescentemente enredado em tecnologias comunicacionais?

Há um grande paradoxo obnubilando a humanidade. Se, por um lado, ela é a responsável pelo desenvolvimento das tecnologias, por outro está, cada vez mais, 
dependente de suas próprias invenções. Um projeto pós-humano, por assim dizer, de emancipação é apresentado em "Dos diferentes corpos: humano, animal, coisa". "Cabe-nos projetar um corpo (ou corpos) diferente capaz de nos tornar mais livres e mais eficientes. (...) tal empresa está associada à estrutura de nosso sistema nervoso e de nosso cérebro" (FELINTO \& SANTAELLA, 2012, p. 104). Ao colocar em discussão as estruturas nervosas e mentais dos seres humanos é possível que esse capítulo desperte no leitor amplas reflexões e questionamentos profundos sobre sua própria condição.

Das profundezas oceânicas abissais às páginas do livro uma criatura surge: é o Vampyroteuthis infernalis cuja primeira aparição no universo flusseriano aconteceu em 1987 em um ensaio-ficção que o filósofo publicou em parceria com o artista e biólogo Louis Bec. A "lula-vampiro do inferno" - um dos seres mais distantes espacialmente do homem na terra - é escolhida por Flusser para um experimento de alteridade radical permitindo a ele articular uma série de questões presentes no conjunto de sua obra, como racionalidade científica e seus limites, relação entre arte, memória e transmissão de informações, materialidade, finitude e morte. "É ele que habita todas as nossas profundezas e nós habitamos ele. E esse encontro de si próprio no outro extremo do mundo é o derradeiro propósito de todas as explorações humanas (FLUSSER, s/data, p. 55 apud FELINTO \& SANTAELLA, 2012, p. 121).

Os pesquisadores apontam que o debate sobre o pós-humanismo na atualidade tensiona diversos conceitos que ao longo dos séculos buscaram definir o que é o humanismo, principalmente aquele que se firmou na modernidade, alicerçado no sujeito liberal, produto das dicotomias cartesianas e dos valores do Iluminismo. Entre os autores acionados nesse capítulo está Heidegger, que na obra "Ser e Tempo", publicada em 1927, posicionou-se contra o humanismo, não para preconizar o "não humano", mas para dar à humanidade "um sentido tão decisivo que não foi e não será pensado por qualquer metafísica" (FELINTO \& SANTAELLA, 2012, p. 139).

Finalmente, o posicionamento de três expoentes da teoria da mídia alemã com relação ao pós-humanismo é explicitado. São eles: Niklas Luhmann, Friedrich Kittler e o próprio Vilém Flusser que, embora nascido em Praga, foi educado na cultura alemã.

Em Luhmann, o pós-humano cibernético é o humano metamorfoseado por sua reconexão nas condições sistêmicas e globais de sua possibilidade evolucionária. Por sua vez, o método pós-humanista de Kittler retira o foco centrado no sujeito, 
característico da maioria dos estudos de mídia, para reconstruir o ser humano a partir do maquínico. Já Flusser, enxerga o humano como sempre apto a reinventar-se nas suas interações com a tecnologia. Diferentemente de Kittler, ou mesmo Luhmann, não é um pós-humanista radical, embora seja indiscutível sua ruptura com o modelo tradicional do sujeito humano liberal.

Despido do dualismo cartesiano, Spinoza (1632-1677) concebe Deus como matéria e não como puro espírito, contrariando a tradição teológico-metafísica que representa a divindade como ser transcendente, dotado de vontade onipotente e entendimento onisciente. Para ele, todas as coisas (inclusive os homens) são modos ou expressões da substância única, que também é causa de si mesma: Deus. Um dos desdobramentos das reflexões do filósofo refere-se ao acaso dos encontros dos corpos, mais precisamente dos bons e dos maus encontros. Estes diminuem ou mesmo aniquilam a potência de agir, enquanto aqueles a aumentam ao afetarem os indivíduos de forma alegre.

Recortando do pensamento de Spinoza a ideia dos bons e dos maus encontros, é interessante ressaltar que "O Explorador de Abismos: Vilém Flusser e o Pós-Humanismo" resulta de uma série de bons encontros, sendo que dois deles foram fundamentais para a criação da obra: o interesse mútuo de Felinto e Santaella pelo tema do pós-humanismo e o decisivo encontro de ambos com o pensamento de Flusser que povoou suas conversas sobre arte, literatura e semiótica durante longas caminhadas por florestas silenciosas e friorentas no inverno de 2011 em Kassel, na Alemanha.

No que diz respeito aos leitores, cabe a cada um, a partir de um provável encontro com a obra, sentir se ela afeta-o de forma alegre ou triste. Se a resposta for "alegre" é provável que houve um bom encontro e que a potência de agir, diria Spinoza, foi estimulada. Resta agora transformá-la em ação, explorando os abismos flusserianos em busca dos mais altos píncaros do saber.

Por outro lado, parece claro que os que abominam técnicas e tecnologias e veem nelas apenas instrumentos de controle e dominação humana podem ter dificuldade em assumir que a leitura da obra resultou em um bom encontro. Mesmo nesse caso sua fruição parece válida, se não para assumir o pós-humanismo como projeto existencial, pelo menos para conhecer o rico universo conceitual de Vilém Flusser e, quem sabe a 
partir desse manancial filosófico, conceber outras possibilidades humanas ou mesmo pós-humanas de viver.

Uma lacuna da obra, que não interfere no cumprimento de seus objetivos, é não aprofundar a discussão do pós-humanismo no contexto do Brasil, país marcado por contradições sociais abissais, onde, não raro, a miséria aproxima seres humanos a estados animalescos de existência, a milhões de anos luz de qualquer tecnologia, ciência e, por que não, pós-humanidade.

Mesmo um debate superficial que situasse o pós-humanismo perante o subdesenvolvimento brasileiro e admitisse objetivamente a existência de milhares de pessoas vivendo em condições subumanas já seria relevante para iniciar-se, utilizando aqui um conceito de Oswald de Andrade, uma antropofagização do tema.

Um passo da humanidade em direção ao pós-humanismo seria capaz de iniciar um processo de reversão das mazelas e das contradições do humanismo? Humanismo este definido pelos próprios autores como "uma técnica de programação de mentes e corpos, sustentada por mídias, códigos, aparatos e tecnologias". Se a resposta for afirmativa, as escolhas que a humanidade fizer no presente poderão ser decisivas para seu futuro no planeta Terra como jamais o foram em outros períodos da História.

\section{REFERÊNCIAS}

ANDRADE, Oswald de. O manifesto antropófago. In: TELES, Gilberto Mendonça. Vanguarda europeia e modernismo brasileiro: apresentação e crítica dos principais manifestos vanguardistas. Petrópolis: Vozes, 1976.

DELEUZE, Gilles \& GUATTARI, Félix. Mil platôs: capitalismo e esquizofrenia. v. 1. Rio de Janeiro: Editora 34, 2011.

FELINTO, Erick; SANTAELLA, Lucia. O explorador de abismos: Vilém Flusser e o pós-humano. São Paulo: Paulus, 2012.

FLUSSER, Vilém. Filosofia da caixa preta - ensaios para uma futura filosofia da fotografia. São Paulo: Editora Hucitec, 1985. 
MATTELART, Armand; MATTELART, Michele. História das teorias da comunicação. São Paulo: Loyola, 1999.

SPINOZA, Benedictus de. Pensamentos metafísicos; Tratado da correção do intelecto; Ética. In: Os pensadores. Tratado político; Correspondência. São Paulo: Abril Cultural, 1983. 